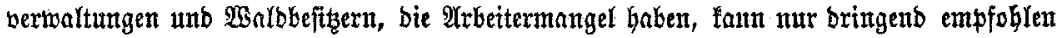

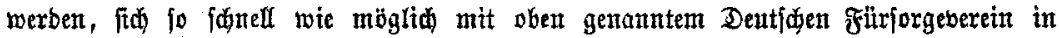
SBerbinbing gut fetsent.

\title{
Redaftions: $\mathfrak{W}_{\mathfrak{e}}$ hfel.
}

Die Rebaftion bes "Eentrafblattes fïr bas gejammte Forftwejen", zugleid Drgan

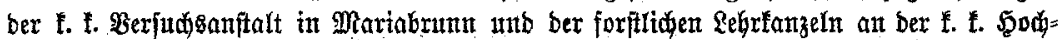
jăule fïr Bobenfuttur in Bien, ift nad bem Iob bes bisberigen Rebafteurs, bes

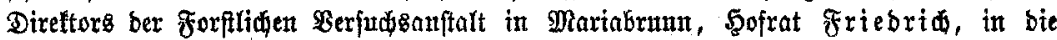

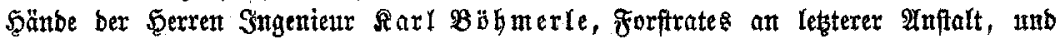

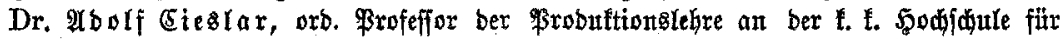
Bobentultur in $\mathfrak{B i e n}$ iibergegangen.

\section{Dienftes = Ladhriditetr.}

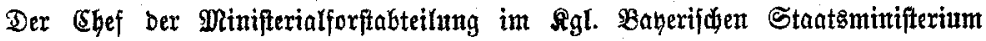

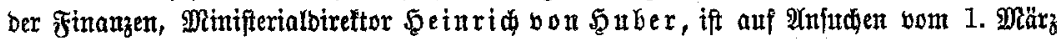

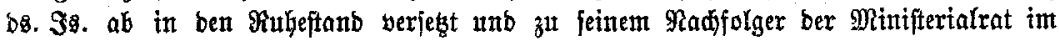
gleidfen Minifferium $\mathfrak{R a r l}$ von $\mathfrak{B r a z a}$ unter Beförberung zum Minifterialbireftor exmannt worben.

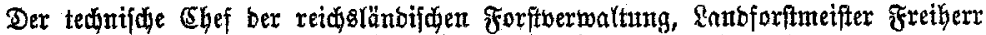

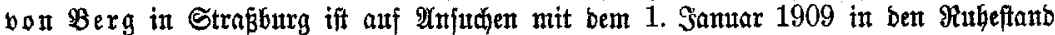

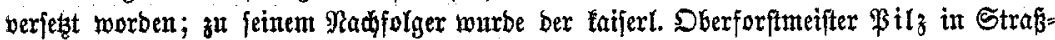
burg unter Befürberung zunt Lanbforftnteifter ernaunt.

\section{Wald $\{$ ament $=\mathbb{E}$ Ente.}

Die Firma 5einrid Reller Sobn, Darmftabt, bittet bem neufiden Beridt nađjzutragen, baß bie Riefernzapfenernte in Belgien, bie z. 3t. als fer in letzter 9 aummer

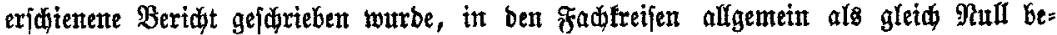
traditet tourbe, fid fpäterbin als etwas günffiger barftelfte, inbem 8 elgien bod ein alfer=

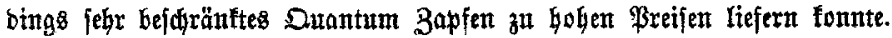

